American J. of Engineering and Applied Sciences 1 (2): 157-160, 2008

ISSN 1941-7020

(C) 2008 Science Publications

\title{
Equilibrium Adsorption of Hydrogen and Methane on 5A Molecular Sieve
}

\author{
${ }^{1}$ Hayder A. Abdul Bari, ${ }^{2}$ Abdul Halim A.K. Mohammed, \\ ${ }^{2}$ Abbas K.M. Shua'ab and ${ }^{1}$ Rosli Bin Mohd. Yunus \\ ${ }^{1}$ Faculty of Chemical and Natural Resources Engineering, University Malaysia Pahang, \\ Kuantan, 25000, Pahang, Malaysia \\ ${ }^{2}$ Chemical Engineering Department, College of Engineering,Baghdad University, \\ P.O. Box 47024, Baghdad, Iraq
}

\begin{abstract}
Adsorption equilibrium isotherms of hydrogen and methane are reported for the temperature range 303-333 $\mathrm{K}$ and pressure up to $4 \mathrm{MPa}$. The adsorbent was 5A molecular sieve (supplied by Rhone Poulenc industries Ltd.). Experimental data were obtained using a static system for gas-solid adsorption. The Langmuir adsorption equilibrium equation gave excellent predictions. Adsorption of hydrogen and methane on $5 \mathrm{~A}$ molecular sieve is purely physical since the isosteric heat of adsorption was found to be equal to 9.889 and $14.804 \mathrm{~kJ} \mathrm{~mole}^{-1}$ for hydrogen and methane, respectively.
\end{abstract}

Key words: Molecular sieve, adsorption, hydrogen, methane, Static system, isosteric heat

\section{INTRODUCTION}

The increasing importance of adsorption processes for the separation of gaseous mixtures is due to the high selectivity and adsorption capacity of solid adsorbents, the less extreme operation conditions needed and the small energy consumption required. Adsorption is becoming a competitive operation that can advantageously substitute for other separation operations such as distillation or absorption. The advantages are especially attractive when the problem is the separation of light gases such as methane, ethane, propane and other typical hydrocarbons of gaseous refinery streams, since their separation by distillation or absorption requires expensive high pressure units.

The separation of hydrogen from methane and other hydrocarbons is an important industrial process in the petroleum refining and synthetic gas processing industries among others. 5A molecular sieve has been used commercially for the purpose. Yet, knowledge of adsorption of hydrogen and methane on $5 \mathrm{~A}$ molecular sieve is limited. However, some interest has been shown in adsorption of hydrogen and methane on $5 \mathrm{~A}$ molecular sieve due to the necessity of recovering hydrogen from refinery off-gas streams. A significant effort in this area has been undertaken at the Iraqi north refineries.

Data on the adsorption of hydrogen and methane on molecular sieves are scarce in the literature. Some low-pressure data have been reported for Linde 5A and
13X molecular sieve, where methane was found to be preferentially adsorbed on the former molecular sieve ${ }^{[1]}$. Limitation are placed on the usefulness of these data for the design of commercial molecular sieve-based separation systems, since a large part of these data was obtained at temperatures and pressures which are not ordinarily considered practical from a commercial stand point.

In this research reported herein, fundamental equilibrium adsorption data obtained for hydrogen and methane on a single sample of $5 \mathrm{~A}$ molecular sieve. To simulate refinery off-gas conditions, the temperature ranged from ambient to $60^{\circ} \mathrm{C}$ and the pressure to 4 $\mathrm{MPa}$. These data are of value in process and design studies of $5 \mathrm{~A}$ molecular sieve -based separation systems involving the separation of hydrogen from refinery off-gases.

Experimental work: A diagram of the apparatus is shown in Fig. 1. All tubing was thick wall stainless steel, to minimize the dead volume. The tubing was connected by Crawford Swagelock compression fittings. Parker CPI series severe service union bonnet valves, with a hardened ball stem tip, were chosen because of their durability under repetitive use. A metal stem tip was selected instead of a soft stem tip to avert destruction of the valve seat in the event that particulate matter should escape from the adsorption chamber, enter the valve and score the valve seat.

Corresponding Author: Hayder A. Abdul Bari, Faculty of Chemical and Natural Resources Engineering, Universiti Malaysia Pahang, Kuantan, 25000, Pahang, Malaysia Tel: +60 123495130 


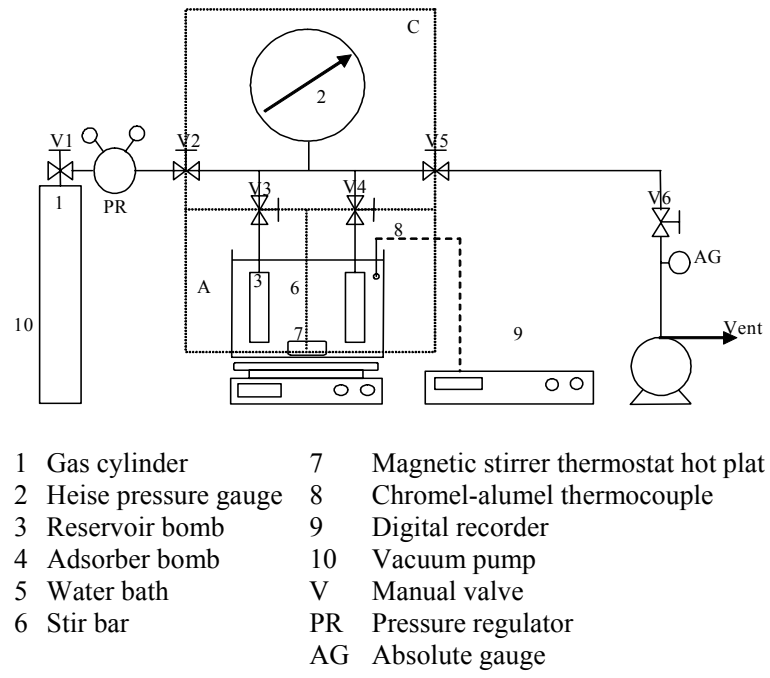

Fig. 1: Diagram of apparatus used for adsorption equilibrium measurement

The adsorption chamber and reservoir were $20 \mathrm{~cm}^{3}$ iron sample cylinders. Entrainment of adsorbent particles in the tubing and valving system was prevented by employing a dual screen method. This was accomplished by inserting Pyrex glass wool and a conical brass wire mesh screen, capable of containing particles.

The gas pressure was measured via a Heise bourdon gauge with a $430 \mathrm{~mm}$ diameter dial and a pressure range from $0-6891 \mathrm{kPa}$. The accuracy of the gauge was rated at $0.1 \%$ of the full scale and the sensitivity at $0.02 \%$ of the full scale at all points. The pressure gauge enclosed a dead volume of approximately $30 \mathrm{~cm}^{3}$.

A water bath was employed to provide a constant temperature environment up to $353 \mathrm{~K}$ for both the adsorber and the reservoir. The bath was thermo-stated and vigorously mixed by using a magnetic stirrer thermo-stat hot plate. The temperature of the bath was continuously measured and recorded via a digital recorder and a thermocouple wire, calibrated with mercury thermometer.

The whole equipment was evacuated by vacuum pump and absolute gauge pressure prior to each experiment. The feed and carrier gas supplied from cylinders were regulated by pressure regulators.

The volume of the reservoir and the adsorber (together with the Swagelock fittings) and the other sections of the system were measured manometrically using nitrogen gas. Section $\mathrm{C}$ was charged with nitrogen gas to a known pressure $\mathrm{P}_{1}=4 \mathrm{MPa}$. Valve 5 was connected to a standard known volume previously evacuated cylinder vessel $\mathrm{V}_{1}=1$ liter and opened until equilibrium was reached with a new pressure $\mathrm{P}_{2}$, then the volume of section $\mathrm{C}$ was determined by the ideal gas equation of state:

$$
\mathrm{V}_{\mathrm{C}}=\frac{\mathrm{P}_{2} \mathrm{~V}_{1}}{\mathrm{P}_{1}-\mathrm{P}_{2}}
$$

The volume of section A and B were determined in the same manner.

The granular adsorbent (10 g) was packed into the adsorption vessel and degassed for overnight under vacuum at a pressure of less than $3 \mathrm{~Pa}$ to clean the adsorbent. This pretreatment enabled us to make adsorption measurements without changing the adsorbent. After the adsorbent had been regenerated, the vacuum pump was switched off. The water bath with electrical stirrer thermo-stated hot plate was switched on until constant temperature was reached.

The procedure for measuring equilibrium adsorption was as follow:

Section $\mathrm{A}$ and $\mathrm{C}$ were pressurized with the adsorbate, corresponding to a pressure $\mathrm{P} 3$ then the number of moles of the adsorbate was estimated according to the relation:

$$
\mathrm{n}_{1}=\frac{\mathrm{P}_{3}\left(\mathrm{~V}_{\mathrm{C}}+\mathrm{V}_{\mathrm{A}}\right)}{\mathrm{RT}}
$$

Passage of gas to section $B$ was allowed until equilibrium $\left(\triangle \mathrm{P} \leq 3 \mathrm{kPa} \mathrm{h}^{-1}\right)$. The equilibrium pressure was recorded as $\mathrm{P} 4$.

Adsorber was isolated from the system. The number of moles of the adsorbate was estimated according to the relation:

$$
\mathrm{n}_{2}=\frac{\mathrm{P}_{4}\left(\mathrm{~V}_{\mathrm{C}}+\mathrm{V}_{\mathrm{A}}+\mathrm{V}_{\mathrm{B}}\right)}{\mathrm{RT}}
$$

The amount adsorbed of the adsorbate at partial pressure equal to $\mathrm{P}_{4}$ is determined according to a material balance equation:

$$
\mathrm{q}=\frac{\mathrm{n}_{1}-\mathrm{n}_{2}}{\mathrm{~W}}
$$

\section{RESULTS AND DISCUSSION}

The partial pressure and temperature ranges were chosen for each component in viewing to the expected values in the refinery off-gas properties and component vapor pressure, which almost must be greater than the 
component partial pressure under specified temperature, to avoid condensation of gases on the adsorbent.

The experimental results for single gas equilibrium were fitted with Langmuir and Freundlich equations. BET and other equations that represent multi-layer adsorption were excluded because it is unlikely that multi-layer adsorption could have occurred in this study were all temperatures above the critical ${ }^{[2]}$.

The Langmuir equation takes the form:

$$
\frac{\mathrm{q}}{\mathrm{q}_{\mathrm{m}}}=\frac{\mathrm{BP}}{1+\mathrm{BP}}
$$

The coefficients B and qm depend on temperature in accordance to the following Eq:

$$
\begin{aligned}
& \mathrm{q}_{\mathrm{m}}=\mathrm{a}_{1} \mathrm{~T}^{\mathrm{a}_{2}} \\
& \mathrm{~B}=\mathrm{a}_{3} \mathrm{e}^{\mathrm{a}_{4} / \mathrm{T}}
\end{aligned}
$$

The Freundlich equation takes the form:

$$
\mathrm{q}=\mathrm{k}_{\mathrm{F}} \mathrm{P}^{\mathrm{n}_{\mathrm{F}}}
$$

The coefficients $\mathrm{k}_{\mathrm{F}}$ and $\mathrm{n}_{\mathrm{F}}$ depend on temperature in accordance to the following equations:

$$
\begin{aligned}
& \mathrm{k}_{\mathrm{F}}=\mathrm{b}_{1} \mathrm{~T}^{\mathrm{b}_{2}} \\
& \mathrm{n}_{\mathrm{F}}=\mathrm{b}_{3}+\mathrm{b}_{4} / \mathrm{T}
\end{aligned}
$$

The objective function (average relative error) used in the minimization routine was defined as:

$$
E=\frac{1}{N} \sqrt{\sum_{i=1}^{N}\left(\frac{q_{i, e x p}-q_{i, \text { cal }}}{q_{i, e x p}}\right)^{2}}
$$

Where $\mathrm{N}$ is the number of experimental points and $\mathrm{q}_{\mathrm{i}, \exp }$ and $\mathrm{q}_{\mathrm{i}, \mathrm{cal}}$ are the experimental and calculated values of $\mathrm{q}_{\mathrm{i}}$, respectively.

The calculated constants for the two model equations along with the average relative error values were shown in Table 1. The table shows that Langmuir equation correlates the experimental data with mean average relative error of $0.41 \%$ while $1.08 \%$ for Freundlich equation. Therefore, the best fit was achieved with Langmuir equation. The experimental equilibrium data was correlated by Langmuir equation and shown in Fig. 2 and 3.

All curves for any specified gas the adsorbent are similar in shape and are of the classic adsorption
Table 1: Summary of single gas adsorption isotherms results

\begin{tabular}{llllll}
\hline Adsorbate & $\mathrm{a}_{1}$ & $\mathrm{a}_{2}$ & $\mathrm{a}_{3}$ & $\mathrm{a}_{4}$ & $\% \mathrm{E}$ \\
\hline $\mathrm{H}_{2}$ & $4.63 \times 10^{-1}$ & -0.92 & $5.61 \times 10^{-9}$ & 841.47 & 0.31 \\
$\mathrm{CH}_{4}$ & $8.25 \times 10^{-1}$ & -0.99 & $3.24 \times 10^{-7}$ & 705.96 & 0.51 \\
Adsorbate & $\mathrm{b}_{1}$ & $\mathrm{~b}_{2}$ & $\mathrm{~b}_{3}$ & $\mathrm{~b}_{4}$ & $\% \mathrm{E}$ \\
$\mathrm{H}_{2}$ & $9.79 \times 10^{-3}$ & -2.79 & 0.84 & 10.46 & 0.38 \\
$\mathrm{CH}_{4}$ & $4.21 \times 10^{-44}$ & 15.42 & -0.87 & 385.45 & 1.77 \\
\hline
\end{tabular}

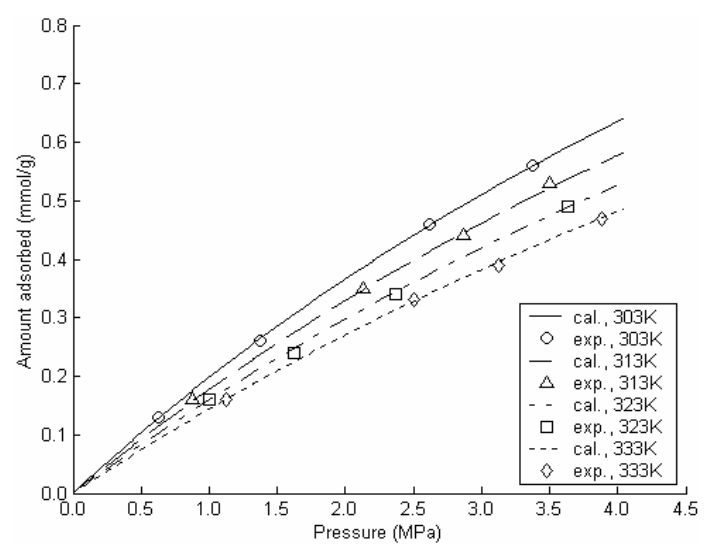

Fig. 2: Adsorption equilibrium isotherms for the system Hydrogen -5A molecular sieve correlated with Langmuir equation

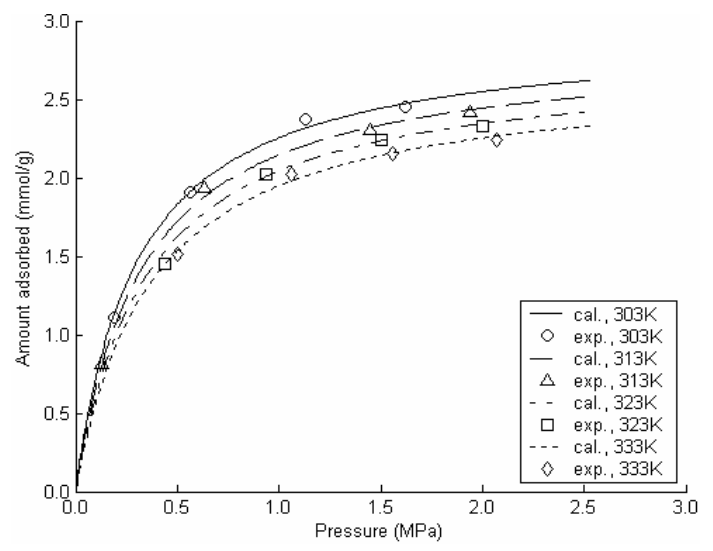

Fig. 3: Adsorption equilibrium isotherms for the system Methane-5A molecular sieve correlated with Langmuir equation

isotherm form. However, it was concluded that the strength of adsorption for $\mathrm{CH}_{4}$ is greater than for $\mathrm{H}_{2}$, since it was recognized that $\mathrm{CH} 4$ has isotherms with greater slopes at $\mathrm{P} \rightarrow 0$, which indicates that the affinity for adsorption of $\mathrm{CH}_{4}$ is greater than for $\mathrm{H}_{2}$.

The results also indicate that there is a fair correlation for the amount of adsorption on an adsorbent correspond to increased adsorption with higher gas molecular weight or critical temperature. 
Table 2: Heat of adsorption and condensation for gases

\begin{tabular}{lll}
\hline $\begin{array}{l}\text { Component } \\
\left.\mathrm{mole}^{-1}\right)\end{array}$ & $\Delta \mathrm{H},\left(\mathrm{kJ} \mathrm{mole}^{-1}\right)$ & $\Delta \mathrm{H}_{\text {cond }}$ at BP $(\mathrm{kJ}$ \\
\hline $\mathrm{H}_{2}$ & 9.889 & 0.904 \\
$\mathrm{CH}_{4}$ & 14.804 & 8.180 \\
\hline
\end{tabular}

This result is in agreement with published works ${ }^{[3]}$. Also, vapor pressure can be expected to be the predominant factor favoring adsorption. The much less volatile gas is more likely to condense on the surface since it has a much larger relative saturation value $\left(\mathrm{P} / \mathrm{P}^{*}\right)$ than the more volatile one. This result was verified by several authors ${ }^{[4]}$.

Adsorption isotherms for the $\mathrm{H}_{2}$ and $\mathrm{CH}_{4}$ gases on $5 \mathrm{~A}$ molecular sieve at moderate temperature ranges are shown in Fig. 2 and 3. The marked decrease in adsorption with increasing temperature is obvious from these diagrams.

The heat of adsorption $(\Delta \mathrm{H})$ was calculated by application of the Clausius-Clapeyron equation ${ }^{[5,6]}$ at neighboring temperatures. When this equation is applied to the two phase system of gas and adsorbed component on the surface, we get:

$$
\left(\frac{\mathrm{dP}}{\mathrm{dT}}\right)_{\theta}=\frac{\Delta \mathrm{H}}{\mathrm{T}\left(\mathrm{V}-\mathrm{V}_{\mathrm{a}}\right)}
$$

Where $\mathrm{V}$ and $\mathrm{V}_{\mathrm{a}}$ are the volumes per mole of adsorbed component in the gas and on the surface, respectively. $\mathrm{V}_{\mathrm{a}}$ is very small and could be neglected. By assuming the ideal-gas law for $\mathrm{V}$ we get:

$$
\Delta H=-R\left(\frac{d \ln P}{d 1 / T}\right)_{\theta}
$$

Table 2 shows the results of this equation.

In both cases the heats of adsorption are higher than the latent heats of condensation but are low enough to be characterized as physical adsorption.

\section{CONCLUSIONS}

Equilibrium isotherms for single component adsorption of hydrogen and methane on $5 \mathrm{~A}$ molecular sieve can be correlated by Langmuir equation.

The strength of adsorption for methane is greater than for hydrogen on 5A molecular sieve.

The heat of adsorption for both hydrogen and methane on $5 \mathrm{~A}$ molecular sieve, always greater than the latent heat of condensation.

\section{ACKNOWLEDGEMENT}

The authors acknowledge the Chemical Engineering Department, Collage of Engineering, University of Baghdad, for the financial support of the research group.

\section{REFERENCES}

1. Wakasugi, Y., S. Ozawa and Y. Ogino, 1981. Physical adsorption of gases at high pressure. J. Colloidlnterface Sci., 79: 99. http://www.sciencedirect.com/science?_ob=Ar ticleURL\&_udi=B6TFK-3VY4SW5-

$4 \&$ _user $=4406426 \&$ rdoc $=1 \&$ fmt $=$ \&_orig $=\mathrm{S}$ earch\&_sort $=\mathrm{d} \&$ view $=\mathrm{c} \&$ _version $=1 \&$ \&urlVe rsion $=0$ \&_userid $=4406426 \& \mathrm{md} 5=$ fa24e $67 \mathrm{e} 5 \mathrm{a}$ $3984 \mathrm{c} 12 \mathrm{cf} 7 \mathrm{c} 32 \mathrm{ab} 7 \mathrm{a} 74690$

2. Yang, R.T. and J.T. Saunders, 1985. Adsorption of gases on coals and heat-treated coals at elevated temperatures and pressures. I. adsorption of methane and hydrogen from single gases. Fuel, 64: 616.

www.engin.umich.edu/dept/cheme/people/yan gpub.html - 100k

3. Lewis, W.K., E.R. Gilliland, B. Chertow and W.P Cadogan, 1950. Adsorption equilibria: Hydrocarbon gas mixture. Ind. Eng. Chem., 42: 319-1326.

DOI: $10.1021 /$ ie $50487 \mathrm{a} 023$

http://pubs.acs.org/acs/journals/toc.page?incod en $=$ iechad\&indecade $=\&$ involume $=42 \&$ inissue $=7$

4. Hyun, S.H. and R.P. Danner, 1982. Equilibrium adsorption of ethane, ethylene, isobutane, carbon dioxide and their binary mixtures on 13X molecular sieves. J. Chem. Eng. Data, 27: 96-200.

DOI: $10.1021 / \mathrm{je} 00028 \mathrm{a} 029$

http://pubs3.acs.org/acs/journals/toc.page?inco den $=$ jeeaax \&indecade $=\&$ involume $=27 \&$ inissu $\mathrm{e}=2$

5. Octave Levenspiel, 1999. Chemical Reaction Engineering 3rd Edn., John Wiley \& Sons ISBN 0-471-25424-X (cloth : alk. paper) 